\title{
Protective effects of Zhuifeng tougu on collagen-induced arthritis in DBA/1 mice
}

\author{
Wenyi Qin ${ }^{1}$, Jiarong Zhong ${ }^{2}$, Xiaofeng Rong ${ }^{1}$, Yu Zhong ${ }^{1 *}$ \\ ${ }^{1}$ Department of Integrated Traditional Chinese and Western Medicine, The First Affiliated Hospital of Chongqing Medical \\ University, ${ }^{2}$ Department of Cardiology, The Children's Hospital of Chongqing Medical University, Chongqing 40000, China
}

*For correspondence: Email: Zhongyuhgdh56@163.com

Sent for review: 13 July 2018

Revised accepted: 20 November 2018

\begin{abstract}
Purpose: To investigate the protective effects of Zhuifengtougu (ZFTG) on rheumatoid arthritis (RA) using collagen-induced arthritis (CIA) mouse model

Methods: DBA/1 mice were randomly divided into 7 treatment groups $(n=8)$ : normal, positive control (CIA mice), CIA mice + total glucosides of peony (TGP), CIA mice + cyclophosphamide (CPA), CIA mice $+100 \mathrm{mg} / \mathrm{kg}$ ZFTG, CIA mice $+200 \mathrm{mg} / \mathrm{kg}$ ZFTG, and ClA mice $+400 \mathrm{mg} / \mathrm{kg}$ ZFTG. The serum levels of interleukin (IL)-1 $\beta, I L-6, I L-10, I L-17$ and tumor necrosis factor (TNF)-awere measured by enzyme-linked immunosorbent assay (ELISA). Western blot was used to determine the protein expression of B-cell lymphoma 2 (BCL-2), p53 and first apoptosis signal receptor (Fas).

Results: Following drug administration, the arthritic index in CIA mice administered low-dose, mediumdose, or high-dose ZFTG (1.53 - 1.87), TGP (1.75 \pm 0.42$)$, or CPA (1.52 \pm 0.36$)$ was reduced significantly $(p<0.05)$, compared with positive control group $(5.66 \pm 0.73 ; p<0.01)$. Levels of IL-1 $\beta$, IL6, IL-17 and TNF- $\alpha$ in serum and expression of BCl-2, p53, and Fas were also significantly decreased ( $p$ $<0.05)$ in CIA mice administered ZFTG, TGP, or CPA, whereas IL-10 levels increased.

Conclusion: These results suggest that ZFTG exhibit anti-rheumatic activity in CIA mice via modulation of inflammatory cytokines (IL-1 $\beta, I L-6, I L-10, I L-17$ and TNF- $\alpha$ ) and downregulation of the expressions of $B \mathrm{Cl}-2, p 53$, and Fas. Thus, ZFTG is a potential candidate drug for the treatment of RA.
\end{abstract}

Keywords: Zhuifengtougu pill, Rheumatoid arthritis, Cytokines, Bcl-2, Fas, p53

\begin{abstract}
This is an Open Access article that uses a funding model which does not charge readers or their institutions for access and distributed under the terms of the Creative Commons Attribution License (http://creativecommons.org/licenses/by/4.0) and the Budapest Open Access Initiative (http://www.budapestopenaccessinitiative.org/read), which permit unrestricted use, distribution, and reproduction in any medium, provided the original work is properly credited.

Tropical Journal of Pharmaceutical Research is indexed by Science Citation Index (SciSearch), Scopus, International Pharmaceutical Abstract, Chemical Abstracts, Embase, Index Copernicus, EBSCO, African Index Medicus, JournalSeek, Journal Citation Reports/Science Edition, Directory of Open Access Journals (DOAJ), African Journal Online, Bioline International, Open-J-Gate and Pharmacy Abstracts
\end{abstract}

\section{INTRODUCTION}

The global incidence of RA, a common chronic autoimmune disease, is $1 \%[1,2]$. Disability associated with RA poses a serious problem to patients in terms of ability to work, overall health, and quality of life [3-5]. The etiology and exact mechanisms of RA are not well understood. Nonsteroidal anti-inflammatory drugs and immunosuppressants are commonly used treatments for RA. Some natural plant extracts such as Tripterygium wilfordii and Sinomenine could also offset the immune imbalance in RA. Research on traditional Chinese medicine (TCM) for effectively treating RA has been ongoing for some time and continues to grow. However, systematic theoretical support for TCM in the treatment of RA is lacking. 
Most traditional Chinese medicine prescriptions consist of a variety of herbs. Zhuifengtougu (ZFTG), a Chinese patent medicine (approval number: Z20083219), is prepared from 24 Chinese medicinal materials including Radix AconitiPreparata, Radix AngelicaeDahuricae, and Radix Paeoniae Rubra. The ZFTG prescription, coming from the famous ancient Chinese medical manuals, has been proved to have therapeutic effects on osteoarthropathy in the clinic.

The present study was to investigate the protective effects of ZFTG on RA using CIA mouse model and evaluate the potential clinical application of ZFTG for RA.

\section{EXPERIMENTAL}

\section{Experimental animals}

Male DBA/1 mice (Changzhou Cavens Experimental Animal Company, China) were fed standard chow and water and housed in a controlled environment $\left(20-26{ }^{\circ} \mathrm{C}\right.$, relative humidity $40-70 \% 12 \mathrm{~h}$ light/dark cycle). All treatment of mice was in accordance with Guide for the Care and Use of Laboratory Animals by National Research Council [6]. The animal experimental protocols were approved by the The First Affiliated Hospital of Chongqing Medical University Ethics Committee on Animal Research (approval no. CM20170038).

\section{Drugs}

ZFTG (approval number Z20083219, $0.26 \mathrm{~g} /$ pill, Hunan Dekang Pharmaceutical Ltd by Share, Ltd.) was first crushed into powder, and then ZFTG powder $(2.5,5$ or $10 \mathrm{~g})$ was dissolved in $0.9 \% \mathrm{NaCl}$ to obtain low-dose, medium-dose, and high-dose suspensions $(0.05,0.1$ and 0.2 $\mathrm{g} / \mathrm{mL}$, respectively). To prepare Type II collagen (CII) emulsion, CII (Sigma Reagent Company, USA) was dissolved in ethylic acid $(0.1 \mathrm{~mol} / \mathrm{L})$ and emulsified with Freund's Complete Adjuvant (Sigma Reagent Company, USA). Oscillatory emulsification was obtained ( $1 \mathrm{mg}$ CII per $1 \mathrm{~mL}$ ) and stored at $4{ }^{\circ} \mathrm{C}$. Total glucosides of peony (TGP; Li-Hua Pharmaceuticals, Ningbo) and cyclophosphamide (CPA; Hengrui Pharma, Jiangsu) were suspended in $0.9 \% \mathrm{NaCl}$.

\section{Induction of $\mathrm{CIA}$ mice and drug treatment}

Fifty-six eleven-week-old male DBA/1 mice were randomly divided into 7 groups $(n=8)$ : normal; CIA (positive control); CIA + TGP; CIA + CPA; $\mathrm{CIA}+100 \mathrm{mg} / \mathrm{kg}$ ZFTG; CIA + $200 \mathrm{mg} / \mathrm{kg}$ ZFTG; $\mathrm{CIA}+400 \mathrm{mg}$ ZFTG. The mice were immunized with $200 \mu \mathrm{g}$ collagen via injecting into the base of mice tail, and same volume of $0.9 \% \mathrm{NaCl}$ were injected into the mice of normal group. The day of primary injection was set as day 1 .

Booster injection of the same collagen emulsion was performed via intraperitoneal injection on day 21. Besides, mice in ZFTG treatment groups received once daily intragastric administration of ZFTG $(100,200$, or $400 \mathrm{mg} / \mathrm{kg}$, respectively) for 4 weeks. Mice in CIA + TGP and CIA + CPA groups received equal volume daily intragastric administrations of control treatment (TGP or CPA, respectively) over the same period of time. Mice in normal and CIA groups received daily intragastric administrations of the same volume of $0.9 \% \mathrm{NaCl}(4 \mathrm{~mL})$.

On day 28, after CIA was induced, the body weight of mice in each group was determined every 8 days. The arthritis index scores of mice were evaluated by a blinded observer following a previously reported method [7] in which severity was scored for each limb every 3 days, using a scale ranging from $0-4$, where $0=$ no swelling. The maximum possible score for each mouse is $16.0 n$ day 49 , the mice were euthanized and the knee joints obtained. Following standard methods [8], H \& E staining (hematoxylin and eosin) was carried out. Histopathological damage was scored by a blinded observer. Synovial hyperplasia was evaluated with a semiquantitative scoring system (scale ranging form $0-4$, where $0=$ without hyperplasia, $1=$ low hyperplasia, 2 = medium hyperplasia, with $2-4$ layers of synovial cells affected, $3=$ severe hyperplasia, with $\geq 4$ layers of synovial cells affected, $4=$ total destruction of joint architecture, defined as erosion of cartilage and bone, as well as disappearance of joint space.

\section{Evaluation of serum levels of inflammatory cytokines and expressions of Bcl-2, Fas, and p53}

On day 28-35, blood samples were obtained from the orbital plexus. Serum levels of IL-1 $\beta$, IL6 , IL-10, IL-17 and TNF- $\alpha$ were determined with ELISA kits (Jingmei Biotech, Beijing). On day 4249 , the synovial tissues of knee joints were extracted. Protein expressions of $\mathrm{Bcl}-2$, Fas, and p53 were determined by Western blot (Sai Bao Biotechnology, Shanghai) as described previously [9].

\section{Statistical analysis}

Data are presented as mean \pm standard deviation (SD) and were analyzed by one-way analysis of variance (ANOVA) to determine 
significant difference. $P<0.05$ was set as the significance threshold. SPSS 17.0 was employed for statistical analyses.

\section{RESULTS}

\section{Body weight and arthritic index of mice CIA group}

As shown in Figure $1 \mathrm{~A}$, the body weight of mice in normal and CIA groups was $18 \pm 1 \mathrm{~g}$ at the beginning of the experiment and naturally increased to $22 \pm 1$ gat day 21 . Following booster immunization on day 21 , the body weight of mice in CIA group stopped growing, while the body weight continued to increase in the normal mice, leading to a significant $(p<0.05)$ difference between these two groups at all time points assessed from day 35 through day 70 . However, the overall effect size was modest. There were no deaths in either group.

Following immunization on day 21 , the mean arthritis index in the CIA mice increased gradually over time (Figure 1B). Arthritis index scores were recorded for a total of $10 \mathrm{CIA}$ mice every 8 days.

A

B
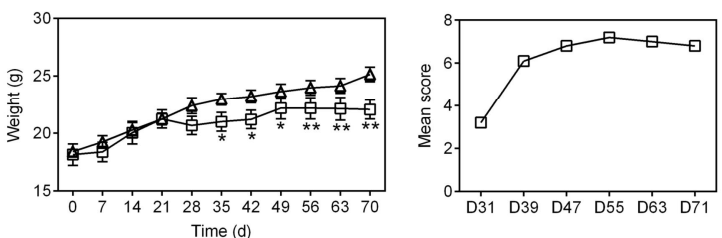

Figure 1: A: Body weight changes in CIA mice and normal group $\left({ }^{*} p<0.05,{ }^{* *} p<0.01 \mathrm{CIA}\right.$ group vs normal group) $\Delta$ Normal, $\square$ ClA. B: Mean arthritis index in CIA mice

\section{Effects of ZFTG on CIA mice}

After ZFTG treatment for 4 weeks, the mean body weight of mice in CIA + ZFTG groups (high- dose: $21.9 \pm 0.6 \mathrm{~g}$, medium-dose: $21.7 \pm 0.4 \mathrm{~g}$, low-dose: $21.8 \pm 0.5 \mathrm{~g}$ ) was similar that in CIA group $(21.8 \pm 0.6 \mathrm{~g})$, while the body weight of mice in CIA + CPA group (18.8 $\pm 0.7 \mathrm{~g})$ was significantly decreased (Table 1).The arthritis index scores in CIA + ZFTG groups (high-dose: $1.53 \pm 0.27$, medium-dose: $1.62 \pm 0.33$, lowdose: $1.87 \pm 0.41), \mathrm{ClA}+\mathrm{TGP}$ group (1.75 \pm $0.42)$, and $\mathrm{CIA}+\mathrm{CPA}$ group (1.52 \pm 0.36 ) were significantly lower than that in CIA group (5.66 \pm $0.73, p<0.01)$. The swelling ratio remarkedly increased in CIA group (48.5 $\pm 7.2, p<0.01)$ compared with normal group, while ZFTG, TGP, or CPA administration could significantly suppress the enhanced swelling ratio induced by Cll $(p<0.01)$. It should be noted that there was no significant difference in the arthritis index, swelling ratio, and synovial hyperplasia between $\mathrm{CIA}+200 \mathrm{mg} / \mathrm{kg}$ ZFTG group and $\mathrm{CIA}+400$ $\mathrm{mg} / \mathrm{kg}$ ZFTG group.

Swelling ratio: (post-inflammatory foot volume / pre-inflammatory foot volume -1) $\times 100 \%$; synovial hyperplasia : 0 = without hyperplasia, 1 = low hyperplasia, 2 = medium hyperplasia, with 2-4 layers of synovial cells affected, $3=$ severe hyperplasia, with $\geq 4$ layers of synovial cells affected4 = total destruction of joint architecture; \#\# $p<0.01$ ClA group vs normal group; * $p<$ $0.05 ;{ }^{* *} p<0.01 \mathrm{CIA}+\mathrm{ZFTG}$ vs CIA group

SERUM LEVELS OF CYTOKINES TNF-A, IL-1B, IL-6, IL-10 AND IL-17

Compared with normal group, serum levels of pro-inflammatory cytokines TNF- $\alpha$, IL-1 $\beta$, IL-6, and IL-17 in CIA group increased significantly, and that of anti-inflammatory cytokine IL-10 decreased remarkedly (Figure 2). After administration of ZFTG, CPA, or TGP, serum levels of TNF- $\alpha$, IL-1 $\beta$, IL- 6 , and IL-17 in ZFTG, CPA, or TGP treatment groups decreased and that of IL-10 increased $(p<0.01)$. The effects of ZFTG on CIA mice were dose-dependent.

Table 1: Effect of ZFTG on CIA mice (Mean $\pm S D, n=8$ )

\begin{tabular}{cccccc}
\hline Group & $\begin{array}{c}\text { Dose } \\
(\mathbf{m g} / \mathbf{k g})\end{array}$ & $\begin{array}{c}\text { Body } \\
\text { weight }(\mathbf{g})\end{array}$ & $\begin{array}{c}\text { Arthritis } \\
\text { index }\end{array}$ & $\begin{array}{c}\text { Swelling ratio } \\
(\%)\end{array}$ & $\begin{array}{c}\text { Synovial } \\
\text { hyperplasia score }\end{array}$ \\
\hline Normal & $\mathrm{NA}$ & $22.4 \pm 0.7$ & 0 & $0.33 \pm 2.1$ & 0 \\
CIA & $\mathrm{NA}$ & $21.8 \pm 0.6$ & $5.66 \pm 0.73 \# \#$ & $48.5 \pm 7.2^{\# \#}$ & $2.87 \pm 0.61 \# \#$ \\
CIA + CPA & 20 & $18.8 \pm 0.7$ & $1.52 \pm 0.36^{* *}$ & $8.3 \pm 3.77^{* *}$ & $0.43 \pm 0.13^{* *}$ \\
CIA + TGP & 1 & $22.1 \pm 0.5$ & $1.75 \pm 0.42^{* *}$ & $11.6 \pm 3.2^{* *}$ & $0.56 \pm 0.25^{* *}$ \\
CIA + ZFTG high & 400 & $21.9 \pm 0.6$ & $1.53 \pm 0.27^{* *}$ & $10.8 \pm 2.1^{* *}$ & $0.39 \pm 0.21^{* *}$ \\
$\begin{array}{c}\text { dose } \\
\mathrm{CIA}+\text { ZFTG medium }\end{array}$ & 200 & $21.7 \pm 0.4$ & $1.62 \pm 0.33^{* *}$ & $13.6 \pm 3.4^{* *}$ & $0.46 \pm 0.33^{* *}$ \\
$\begin{array}{c}\text { dose } \\
\text { CIA + ZFTG low dose }\end{array}$ & 100 & $21.8 \pm 0.5$ & $1.87 \pm 0.41^{* *}$ & $15.4 \pm 3.1^{* *}$ & $0.61 \pm 0.27^{* *}$ \\
\hline
\end{tabular}




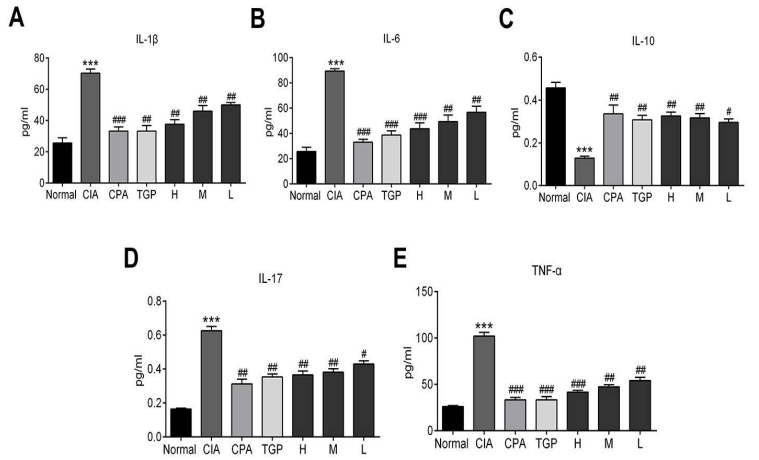

Figure 2: Serum levels of IL-1 $\beta, \mathrm{IL}-6, \mathrm{IL}-10, \mathrm{IL}-17$ and TNF- $\alpha$ (mean \pm SD; 8 mice in each group); (\#p< 0.05, $\# \# p<0.01$ ZFTG group vs CIA group; ${ }^{* *} p<0.001 \mathrm{CIA}$ group vs normal group)

\section{Expressions of $\mathrm{p} 53, \mathrm{Bcl}-2$ and Fas}

Compared with normal group, protein expression of $\mathrm{Bcl}-2$, p53, and Fas in synovial tissues was upregulated significantly in CIA group (Figure 3). Following administration of ZFTG, protein expression of $\mathrm{Bcl}-2$, p53, and Fas was clearly downregulated $(p<0.05)$. Following administration of CPA or TGP, Bcl-2, p53, and Fas expression was down regulated even more markedly.

A

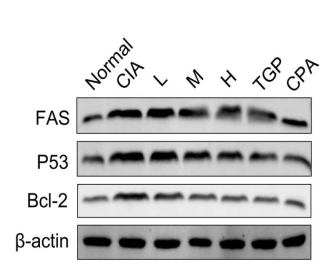

B

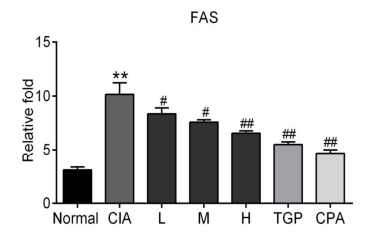

C

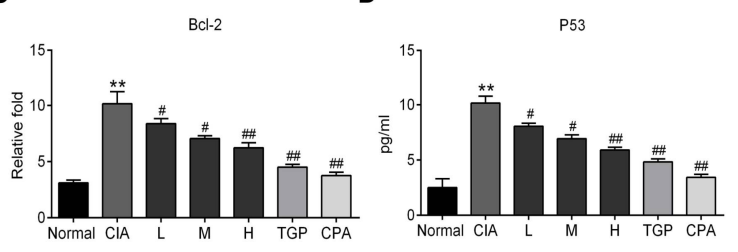

Figure 3: Western blot analyses of Fas, Bcl-2, and $p 53$ expression (each group $n=8$ ). $B$ : The expression of FAS; C: Expression of Bcl-2; D: Expression of p53 (\#p< 0.05, \#\#p<0.01 ZFTG group vs $\mathrm{CIA}$ group; ${ }^{\star *} \mathrm{p}<0.01 \mathrm{CIA}$ group vs normal group)

\section{DISCUSSION}

The CIA model has been recognized as a typical rheumatoid arthritis animal model. Zhang et al $[10,11]$ found that symptoms (redness and swelling) appeared on the posterior foot and ankle joint 24 days after inflammation, then progressed to the anterior foot and tail and continued to aggravate, eventually leading to joint deformity. These clinical manifestations and pathological changes are closely related to RA. The symptoms of CIA mice in this study are consistent with these previous reports.

TGP and CPA have been used for the treatment on RA in the clinic. In this study, CIA mice given medium-dose and high-dose ZFTG (200 and 400 $\mathrm{mg} / \mathrm{kg}$ ) displayed profound reductions in arthritis index scores, swelling ratio scores, and synovial hyperplasia compared with positive control CIA mice. ZFTG did not cause obvious body weight changes or behavioral abnormalities, indicating that administration of ZFTG at doses of 200 and $400 \mathrm{mg} / \mathrm{kg}$ may not induce toxicity.

Previous research indicated that proinflammatory cytokines such as TNF- $\alpha$ and IL-6 can cause destruction of cartilage and bone during RA aggravation. Increasing evidence shows that TNF- $\alpha$ plays an important role in RA and other inflammatory forms of arthritis. In addition, levels of other inflammatory cytokines may be modulated by TNF- $\alpha$. For example, when TNF- $\alpha$ is blocked or inhibited in RA patients, IL$1 \beta$ and IL- 6 decrease correspondingly [12]. IL-6, a pro-inflammatory cytokine, plays an extensive role in immune regulation, inflammation, and oncogenesis. Compared with the normal one, level of IL-6 in sera and synovial fluid was higher in RA patients.

IL-17 is secreted mainly by activated memory CD4 T cells. Following secretion of high levels of IL-17, vessels proliferate, synovium thickens, and pannus formation may occur, leading to arthritis and bone destruction [13,14]. By contrast, IL-10, which is secreted by macrophages, mast cells, and many other cell types, blocks NKL-OPG signaling and inhibits the formation of osteoclasts. Previous studies indicated that RA is associated with $T$ helper cell (Th1/Th2) imbalance. IL-10 and IL-17 are key players in maintaining Th1/Th2 balance, the observation of modulated levels of IL-10 and IL-17 in RA may help explain the mechanism of anti-bone destruction from the perspective of cytokines and molecular biology [15]. ZFTG significantly altered the levels of IL-1 $\beta$, IL- 6 , IL-17, TNF- $\alpha$, and IL-10 consistent with the results in previous studies on effective medications for RA treatment.

Abnormal cell apoptosis can lead to hyperproliferation and hypertrophy of synovial tissue, thereby promoting the occurrence of RA. Fibroblast-like synoviocytes (FLS) are the most important cell type among RA synovial cells. Although the exact mechanism of excessive proliferation remains to be elucidated, lack of apoptosis may be a cause [16]. The abnormal 
proliferation and lack of apoptosis of FLS are closely related to synovial hyperplasia and thickening and may be associated with the pathogenesis of RA [17]. These abnormalities are related to abnormal expression of Fas, p53, $\mathrm{Bcl}-2$ and other genes. Research has found that the expression of anti-apoptotic proteins, including Bcl-2, is markedly increased in RAFLS, suggesting that the apoptosis of FLS was inhibited in CIA mouse model.

Increased expression of p53 could also be detected in RA-FLS. The increased expression of p53 could enhance the apoptosis of fibroblasts [18]. Fas in combination with Fas ligand (FasL) can lead to apoptosis. Impaired cell apoptosis and overexpression of Fas may lead to multiple genetically based diseases. In RA-FLS, there are large quantities of reactive $T, B$ lymphocytes which own low level of apoptosis [19]. After Fas antibody treatment, $50 \%$ of T cells were apoptotic, suggesting that most RA patients with synovial infiltrating $T$ cells expressed Fas antigen. The increased expression of Fas may indicated the enhanced inflammatory response in synovial tissues.

ZFTG treatment may modulate abnormal expression of Fas, p53, and Bcl-2.Following treatment with ZFTG, TGP, or CPA, pathological changes in the synovium of CIA mice can be significantly reduced. The mechanism may be related to increased expression of $\mathrm{Bcl}-2$ and Fas in the synovial cells, which induces apoptosis of the synovial cells and restores the balance of cell proliferation and apoptosis. The expression of p53 protein in the CIA group was high before drug administration, indicating that ZFTG may inhibit hyperplasia of synovial cells and induce apoptosis by inhibiting the expression of p53.

\section{CONCLUSION}

The results of the present study indicates that the levels of anti-CII antibodies and pro-inflammatory cytokines are altered in CIA mice. Mice treated with ZFTG, TGP, or CPA exhibited reduced arthritis index scores, swelling ratio scores, histological arthritic scores, levels of proinflammatory cytokines (IL-1 $\beta$, IL-6, IL-17 and TNF- $\alpha$ ) and expression of anti-Cll genes(Bcl-2, Fas, and p53). This suggests that ZFTG treatment may be effective in managing the development and progression of RA, possibly by increasing the serum levels of the main proinflammatory cytokines and decreasing antiapoptotic proteins.

\section{DECLARATIONS}

\section{Conflict of Interest}

No conflict of interest associated with this work.

\section{Contribution of Authors}

We declare that this work was done by the authors named in this article and all liabilities pertaining to claims relating to the content of this article will be borne by the authors. Wenyi Qin and Jiarong Zhong designed all the experiments and revised the paper. Xiaofeng Rong performed the experiments, Yu Zhong wrote the paper.

\section{REFERENCES}

1. Araki $Y$, Mimura T. The Mechanisms Underlying Chronic Inflammation in Rheumatoid Arthritis from the Perspective of the Epigenetic Landscape. J Immunol Res 2016; 2016(1): 629-682.

2. Catrina Al, Svensson Cl, Malmstrom V, Schett G, Klareskog L. Mechanisms leading from systemic autoimmunity to joint-specific disease in rheumatoid arthritis. Nat Rev Rheumatol 2017; 13(2): 79-86.

3. Karlson EW, van Schaardenburg $D$, van der Helm-van Mil $A H$. Strategies to predict rheumatoid arthritis development in at-risk populations. Rheumatology (Oxford) 2016; 55(1): 6-15.

4. Myasoedova E, Chandran A, Ilhan B, Major BT, Michet CJ, Matteson EL, Crowson CS. The role of rheumatoid arthritis (RA) flare and cumulative burden of $R A$ severity in the risk of cardiovascular disease. Ann Rheum Dis 2016; 75(3): 560-565.

5. Myasoedova E, Crowson CS, Turesson C, Gabriel SE, Matteson EL. Incidence of extraarticular rheumatoid arthritis in Olmsted County, Minnesota, in 1995-2007 versus 1985-1994: a population-based study. J Rheumatol 2011; 38(6): 983-989.

6. Sciences. CfIOoM. International ethical guidelines for biomedical research involving human subjects. Bull Med Ethics 2002; 18(2): 17-23.

7. Li Y-R, Chen D-Y, Chu C-L, Li S, Chen Y-K, Wu C-L, Lin $C-C$. Naringenin inhibits dendritic cell maturation and has therapeutic effects in a murine model of collageninduced arthritis. T J Nutri Biochem 2015; 26(12): 14671478.

8. Simelyte E, Criado G, Essex D, Uger RA, Feldmann M, Williams RO. CD200-FC, a novel antiarthritic biologic agent that targets proinflammatory cytokine expression in the joints of mice with collagen-induced arthritis. Arthritis Rheum 2008; 58(4): 1038-1043.

9. Tsai SW, Hsieh MC, Li S, Lin SC, Wang SP, Lehman CW, Lien CZ, Lin CC. Therapeutic Potential of Sclareol in Experimental Models of Rheumatoid Arthritis. Int $J$ Mol Sci 2018; 19(5): 1351-1364. 
10. $X u J X Z Y$, Zhang $X Z, M a Y Y$. Anti-angiogenic effects of genistein on synovium in a rat model of type II collageninduced arthritis. Journal of Chinese Integrative Medicine 2011; 2(9): 186-193.

11. Zhang Lingling LY, Tong Tong, Wu Yingqi. Establishing method and evaluation indexes of collagen-induced arthritis model in DBA_1 mice. Chinese Pharmacological Bulletin. 2010; 8(26): 1108-1111.

12. Jeong J-W, Lee HH, Lee KW, Kim KY, Kim SG, Hong SH, Kim G-Y, Park C, Kim HK, Choi YW et al. Mori folium inhibits interleukin-1 $\beta$-induced expression of matrix metalloproteinases and inflammatory mediators by suppressing the activation of NF-KB and p38 MAPK in SW1353 human chondrocytes. International Journal of Molecular Medicine. 2016; 37(2): 452-460.

13. Marder W, Khalatbari S, Myles JD, Hench R, Yalavarthi S, Lustig S, Brook R, Kaplan MJ. Interleukin 17 as a novel predictor of vascular function in rheumatoid arthritis. Ann Rheum Dis. 2011; 70(9): 1550-1555.

14. Gullick NJ, Abozaid HS, Jayaraj DM, Evans HG, Scott DL, Choy EH, Taams LS. Enhanced and persistent levels of interleukin (IL)-17(+) CD4(+) T cells and serum IL-17 in patients with early inflammatory arthritis. Clin Exp Immunol. 2013; 174(2): 292-301.
15. Toh ML, Gonzales G, Koenders MI, Tournadre A, Boyle $D$, Lubberts $E$, Zhou $Y$, Firestein GS, van den Berg WB, Miossec P. Role of interleukin 17 in arthritis chronicity through survival of synoviocytes via regulation of synoviolin expression. PLoS One. 2010; 5(10): e13416.

16. Stanford SM, Maestre MF, Campbell AM, Bartok $B$, Kiosses WB, Boyle DL, Arnett HA, Mustelin T, Firestein GS, Bottini N. Protein tyrosine phosphatase expression profile of rheumatoid arthritis fibroblast-like synoviocytes: a novel role of $\mathrm{SH} 2$ domain-containing phosphatase 2 as a modulator of invasion and survival. Arthritis Rheum. 2013; 65(5): 1171-1180.

17. Chung-Tei Chou J-SY, and Miam-Rong Lee. Apoptosis in rheumatoid arthritis \pm expression of Fas, Fas- $L$, p53, and $\mathrm{Bcl}-2$ in rheumatoid synovial tissues. Journal of Pathology. 2001; 19(3): 110-116.

18. Patrice Lassus CB, Olivier Zugasti, Jean-Philippe Chambon, Thierry Soussi, Hibner DIM-MaU. Antiapoptotic activity of p53 maps to the $\mathrm{COOH}$-terminal domain and is retained in a highly oncogenic natural mutant. Oncogene. 1999; 18: 4699 - 4709.

19. Hoa TT HT, Aono H. Novel mechanisms of selective apoptosis in synovial $T$ cells of patients with rheumatoid arthritis. J Rheumatol 1996; 8(23): 1332-1337. 